\title{
Ocean-atmosphere energy exchange over thin, variable concentration Antarctic pack ice
}

\author{
A. P. WORBY \\ Institute of Antarctic and Southern Ocean Studies, University of Tasmania, \\ Sandy Bay, 7005, Australia \\ AND IAN Allison \\ Australian Antarctic Division, Channel Highway, Kingston, 7050, Australia
}

\begin{abstract}
Several recent studies have suggested that much of the winter-time Antarctic ice is thin $(<0.3 \mathrm{~m})$. The presence of extensive areas of thin ice has a significant effect on ocean-atmosphere energy exchange. This is investigated using the Maykut (1978) thin-ice energy-budget model in a study for typical September Antarctic ice and climatic conditions. To study the sensitivity of turbulent heat loss to ice concentrations, the Maykut model is combined with an empirical parameterization for the turbulent fluxes from leads (Andreas, 1980) which takes account of the non-linear relationship between heat loss and lead width (or ice concentration). In this one-dimensional sensitivity study, a constant floe-size is assumed, and ice-concentration variations are simulated by changing the width of the leads between floes. The modelled results, for the floe size considered, indicate that at $80 \%$ ice concentration the turbulent heat loss through the thin ice component can be greater than that from leads. As concentration decreases, however, the fractional loss through the ice, and, hence, the ice-thickness distribution, becomes less significant. For the concentrations lower than $50 \%$, there is little change in turbulent loss with further decrease in ice cover, as the atmosphere effectively "sees" open ocean.
\end{abstract}

\section{INTRODUCTION}

Because the presence of an ice cover modifies the exchanges of energy and mass between the ocean and atmosphere, it is an important component of the climate system. Early estimations, such as those of Fletcher (1969), demonstrated the impact that a continuous sea-ice cover has on the ocean-atmosphere energy exchange within the entire Antarctic sea-ice zone. However, this zone is actually composed of a mixture of different types and thicknesses of ice, plus open water in the form of leads and polynyas, and is not a region of uniform ice of constant thickness. Heat loss from small areas of open water can greatly increase the total energy exchange and, as noted by Maykut (1978), heat losses over thin ice are also substantial and important in any calculation of the overall surface heat balance. Weller (1980) partly allowed for the non-uniform nature of the Antarctic sea-ice zone by dividing the pack into an inner and outer zone characterized by an areal ice concentration (C) of $C \geq 85 \%$ and $15 \% \leq C<85 \%$, respectively. His inner zone was estimated to consist of $10 \%$ open water, $10 \% \quad 0-40 \mathrm{~cm}$ thick ice and $80 \%>40 \mathrm{~cm}$ thick ice, whereas the outer zone had percentages 40,20 and 40, respectively. Weller calculated the total heat flux for each zone as a linear mix of the fluxes for each type of surface and did not take account of non-linear effects arising as a result of the internal boundary layer which is established immediately downwind of a change in surface conditions. The average mid-winter fluxes of turbulent sensible and latent heat over the entire Antarctic pack ice in this model are as much as a factor of six greater than Fletcher's estimates.

Recent studies of ice concentration and thickness in the Antarctic show that a much larger area of the pack is made up of young, thin, first-year ice than previously thought. Gow and others (1982) showed that up to $50 \%$ of the total ice column of the Weddell Sea pack consisted of aggregated frazil crystals formed in leads and polynyas and Wadhams and others (1987) estimated a mean ice thickness of between $0.3 \mathrm{~m}$ and $0.6 \mathrm{~m}$ around $0^{\circ}$ longitude in winter. In the Indian Ocean sector, although the average ice concentration in the spring is as high as $80 \%$, much of the ice is young, thin ice and Allison (1989) estimated an area-weighted thickness of less than $0.4 \mathrm{~m}$. This is supported by Brandt and others (1990), who estimated that more than $20 \%$ of the area within the spring pack consists of largely snow-free ice less than $0.3 \mathrm{~m}$ thick, and that a further $30 \%$ is less than $0.7 \mathrm{~m}$ thick. Jacka and others (1987) also found large areas of young, thin ice and frazil in the pack off East Antarctica, whereas Southern (1989) noted that most of the ice 
in the area south of $57^{\circ} \mathrm{S}$ along the meridians $78^{\circ} \mathrm{E}$ and $75^{\circ} \mathrm{E}$ was thin to medium first-year ice intermixed with immature ice thinner than $0.05 \mathrm{~m}$.

In this paper, we explore the consequences that such a large percentage of thin ice, even in Weller's inner zone, has on the overall energy budget between ocean and atmosphere. We consider particularly the turbulent fluxes and include consideration of the non-linear variation of the total turbulent flux with ice concentration.

\section{ENERGY EXCHANGE OVER THIN ANTARCTIC SEA ICE}

The surface energy budget of snow-free sea ice can be expressed as

$$
(1-\alpha)\left(1-I_{\mathrm{o}}\right) F_{\mathrm{r}}+F_{\mathrm{li}}-F_{\mathrm{lo}}+F_{\mathrm{s}}+F_{\mathrm{e}}+F_{\mathrm{c}}=0,
$$

where $F_{\mathrm{r}}$ represents incoming solar radiation, $\alpha$ the surface albedo, $I_{0}$ the fraction of short-wave radiative energy penetrating into the ice, $F_{\text {li }}$ the incoming long-wave energy, $F_{\text {lo }}$ the emitted long-wave energy, $F_{\mathrm{s}}$ the turbulent sensible heat flux, $F_{\mathrm{e}}$ the turbulent latent heat flux and $F_{\mathrm{c}}$ the conducted heat flux. A negative value indicates that the surface acts as a heat source; a positive value indicates a heat sink.

Maykut (1978) derived a single-layer thermodynamic model of thin sea ice based on the multi-layer model of Maykut and Untersteiner (1971). He expressed sensible and latent turbulent fluxes in bulk aerodynamic form, as

$$
\begin{gathered}
F_{\mathrm{s}}=\rho c_{\mathrm{p}} C_{\mathrm{s}} u\left(T_{\mathrm{a}}-T_{\mathrm{o}}\right) \\
F_{\mathrm{e}}=0.622 \rho L_{\mathrm{s}} C_{\mathrm{L}} u / p_{\mathrm{o}}\left[a\left(f T_{\mathrm{a}}{ }^{4}-T_{\mathrm{o}}{ }^{4}\right)+b\left(f T_{\mathrm{a}}{ }^{3}-T_{\mathrm{o}}{ }^{3}\right)\right. \\
\left.+c\left(f T_{\mathrm{a}}{ }^{2}-T_{\mathrm{o}}{ }^{2}\right)+d\left(f T_{\mathrm{a}}-T_{\mathrm{o}}\right)+e^{\prime}(f-1)\right] .
\end{gathered}
$$

The conducted flux, in terms of a salinity-dependent thermal conductivity, is

$$
F_{\mathrm{c}}=\left[k_{\mathrm{o}}+\left(\beta S_{\mathrm{o}}\right) /\left(T_{\mathrm{o}}-273\right)\right]\left[\left(T_{\mathrm{b}}-T_{\mathrm{o}}\right) / H\right]
$$

and the emitted long-wave energy is

$$
F_{\mathrm{lo}}=-\epsilon \sigma T_{\mathrm{o}}{ }^{4}
$$

Here, the latent and sensible heat transfer coefficients, $C_{\mathrm{L}}$ and $C_{\mathrm{S}}$, respectively, have the values $1.75 \times 10^{-3}$ and $3.0 \times 10^{-3}$, the Stefan-Boltzman constant $\sigma=5.6687 \times$ $10^{-8}$, the conductivity of pure ice $k_{\mathrm{o}}=2.03 \mathrm{~W} \mathrm{~m}^{-1} \mathrm{~K}^{-1}$, the long-wave emissivity of the surface $\epsilon=0.96$, the latent heat of sublimation $L_{\mathrm{s}}=2.8 \times 10^{6} \mathrm{~J} \mathrm{~kg}^{-1}$, the specific heat of air at constant pressure $c_{\mathrm{p}}=1004 \mathrm{~J} \mathrm{~kg}^{-1} \mathrm{~K}^{-1}$, the average air density $\rho=1.3 \mathrm{~kg} \mathrm{~m}^{-3}$, and the temperature at the lower surface of the ice $T_{\mathrm{b}}=-1.8^{\circ} \mathrm{C}$. The $a$, $b, c, d$ and $e^{\prime}$ are constants in an empirical relationship for saturation vapour pressure as a function of $T_{\mathrm{a}}$. $\beta=0.117 \mathrm{~W} \mathrm{~m}^{-2} \mathrm{~kg}^{-1}$ is a constant. $T_{\mathrm{o}}$ is surface temperature (K), $T_{\mathrm{a}}$ air temperature (K), $S_{\mathrm{o}}$ salinity of the ice (parts per thousand), $f$ relative humidity $(\%), p_{\text {o }}$ atmospheric pressure ( $\mathrm{hPa}), \mathrm{H}$ ice thickness $(\mathrm{m})$, and $u$ is wind speed $\left(\mathrm{ms}^{-1}\right)$.

From Equations (1) to (5), Maykut (1978) obtained a fifth degree polynomial solution for $T_{\mathrm{o}}$ in terms of pre- scribed values of $F_{\mathrm{r}}, F_{\mathrm{li}}, T_{\mathrm{a}}, u, f$ and $H$. Values of the turbulent, conducted and emitted long-wave radiation fluxes over thin ice were then obtained from Equations (2), (3) and (4). A major assumption of this single-level thin-ice model is that the temperature gradients within the ice are linear; i.e. the ice essentially has zero heat capacity. This does not apply for thicker ice (Maykut suggests $\geq 0.8 \mathrm{~m}$ ) where temperature gradients have considerable curvature.

We have used Maykut's (1978) model, with input values typical of what we expect for the Antarctic sea-ice zone in September, to estimate heat fluxes over thin Antarctic sea ice. Incoming short-wave radiation is set to $70 \mathrm{~W} \mathrm{~m}^{-2}$ based on coastal Antarctic observations (e.g. Weller, 1967) and incoming long-wave radiation is estimated as

$$
F_{\mathrm{li}}=1.38 e_{\mathrm{a}} \sigma T_{\mathrm{a}}{ }^{4},
$$

where $e_{\mathrm{a}}$ is an effective emissivity, derived by Brunt's formula (after Zillman, 1970) from surface air temperature and humidity, and the constant 1.38 is a cloudiness correction (Budyko, 1963) for a typical low-level cloud cover for latitudes $60^{\circ}-65^{\circ} \mathrm{S}$ in September of $4 / 8$ (Warren and others, 1988). $F_{\mathrm{li}}$ ranges from $200 \mathrm{~W} \mathrm{~m}^{-2}$ at $-20^{\circ} \mathrm{C}(253.2 \mathrm{~K})$ to $265 \mathrm{~W} \mathrm{~m}^{-2}$ at $-5^{\circ} \mathrm{C}(268.2 \mathrm{~K})$. Based on Jenne and others (1974) and Zwally and others (1983), we assume an average wind speed for September of $8 \mathrm{~m} \mathrm{~s}^{-1}$ and an atmospheric pressure of $980 \mathrm{~h} \mathrm{~Pa}$. Surface relative humidity is taken as $90 \%$ and air temperature is treated as a sensitivity parameter in the range $-5^{\circ}$ to $-20^{\circ} \mathrm{C}$ (Jenne and others, 1974). All other variables and constants are the same as those used by Maykut for the central Arctic, including albedo and salinity values as a function of ice thickness, and a value of $I_{0}$ of 0.17 . The fifth degree polynomial expression for $T_{\mathrm{o}}$ was solved using Laguerre's method (e.g. Press and others, 1986: 263-266).

The values of the computed heat fluxes as a function of both air temperature and ice thickness are shown in Figure 1, and the strong dependence of the turbulent fluxes on ice thickness is shown in Figure 2 for air temperatures of $-10^{\circ}$ and $-20^{\circ} \mathrm{C}$. At $-10^{\circ} \mathrm{C}$, the sensible heat component is the dominant mechanism of total turbulent loss for all but the thicker ice and, since the latent term changes little with temperature, sensible loss is even more important at $-20^{\circ} \mathrm{C}$. At $-5^{\circ} \mathrm{C}$, however, the latent flux is similar or greater than the sensible flux.

\section{TURBULENT HEAT LOSS FROM LEADS AND POLYNYAS}

When air blows over a solid-ice or ice-covered surface and suddenly encounters an area of open water, such as a lead or polynya, it experiences both an abrupt change in surface roughness and a dramatic change in surface temperature. Over ice in winter, the surface air temperature will be very close to that of the ice itself which, in the case of first-year Antarctic sea ice of $0.4 \mathrm{~m}$ thickness, will be approximately $-15^{\circ} \mathrm{C}$. In contrast, the water temperature will be at the freezing point, a relatively warm $-1.8^{\circ} \mathrm{C}$. As a result, intensive turbulent mixing takes place over water as wind, which has been blowing over the ice, suddenly encounters these changes in surface characteristics. This dramatically increases the 

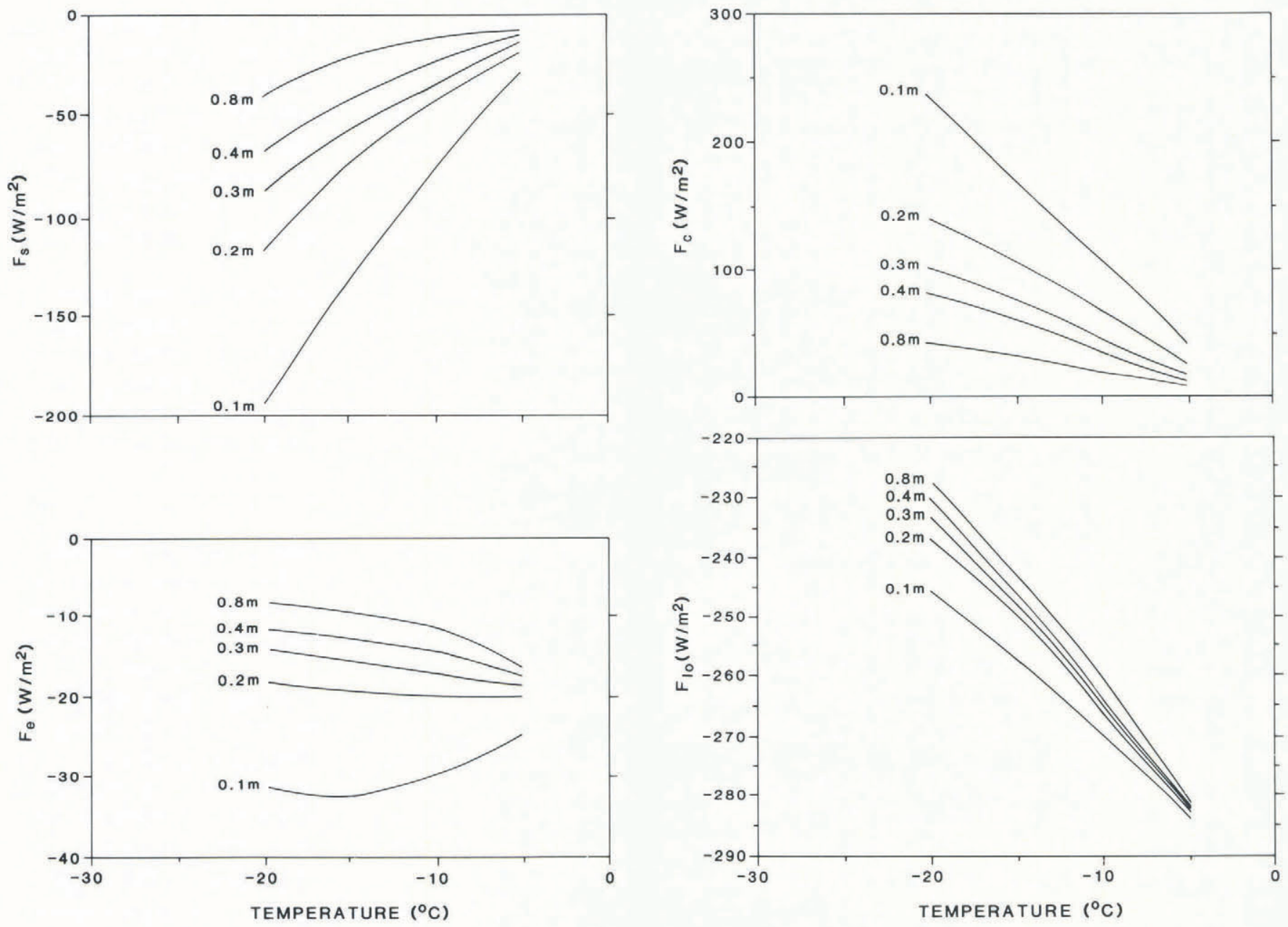

Fig. 1. Variation in the energy-balance components at the surface of thin sea ice with temperature and ice thickness. $F_{s}$ is the sensible heat flux. $F_{e}$ is the latent heat flux. $F_{c}$ is the heat conducted within the ice and $F_{l_{0}}$ the emitted long-wave radiation. The vertical scale is different for each component.

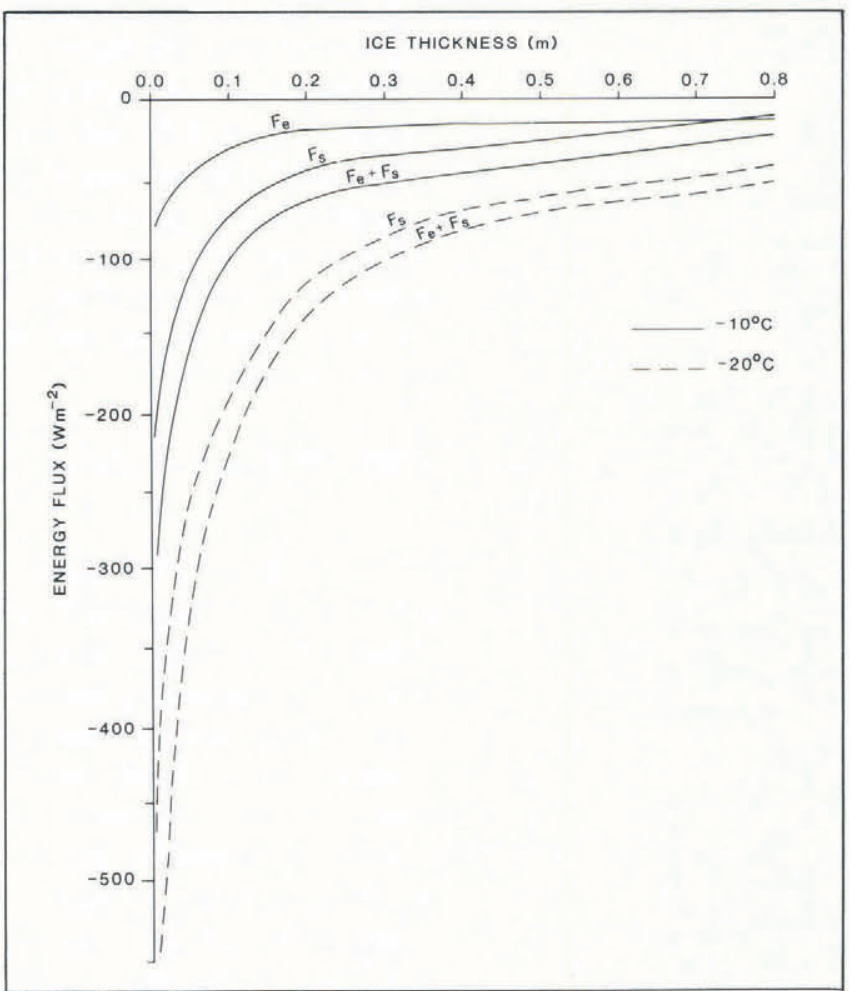

Fig. 2. Variation of turbulent heat flux with ice thickness. magnitude of the turbulent heat fluxes from the surface to the atmosphere. As the air proceeds downwind from the step-change in conditions and is gradually heated, a thermal internal boundary layer forms acting to reduce air-water temperature differences and fluxes. The significant change in heat fluxes immediately downwind of any changes in surface roughness or temperature means that the average heat flux from a lead is fetch dependent. Hence, lead widths must be known to properly estimate the overall heat budget of the pack, and treating the total heat loss simply as a linear mix of heat fluxes over different surfaces is a poor approximation.

Andreas and others (1979) conducted a number of experiments during the AIDJEX Lead Experiment, over both natural and artificial leads up to $35 \mathrm{~m}$ wide. They estimated sensible heat flux upwind and downwind of leads of various widths from measured wind and temperature profiles. Using similar experimental data for the evaporative flux (Andreas, 1982), Andreas (1980) derived an empirical relationship for the estimation of turbulent heat fluxes over leads from bulk quantities

$$
N=0.08 R_{\mathrm{x}}{ }^{0.76},
$$

where $N$, the Nusselt number, is the non-dimensionalised heat flux and $R_{\mathrm{x}}$ is the fetch Reynolds number. Andreas 
and others (1979) define the fetch Reynolds number as

$$
R_{\mathrm{x}}=U_{200} x / \nu
$$

where $U_{200}$ is the wind speed $200 \mathrm{~cm}$ above the upwind surface and $\nu$ is the kinematic viscosity of air $(1.334 \times$ $\left.10^{-5} \mathrm{~m}^{2} \mathrm{~s}^{-1}\right)$. Downwind fetch is symbolised as $x$.

The Nusselt numbers for sensible $\left(N_{\mathrm{S}}\right)$ and latent heat $\left(N_{\mathrm{L}}\right)$ are defined as

$$
N_{\mathrm{S}}=\frac{-F_{\mathrm{s}} x}{\kappa\left(T_{\mathrm{w}}-T_{200}\right)}
$$

and

$$
N_{\mathrm{L}}=\frac{-F_{\mathrm{e}} x}{\rho L_{\mathrm{v}} D_{\mathrm{w}}\left(Q_{0}-Q_{200}\right)},
$$

where $F_{\mathrm{s}}$ and $F_{\mathrm{e}}$ are the average sensible and latent heat losses from the lead, $T_{200}$ and $Q_{200}$ the temperature and specific humidity $200 \mathrm{~cm}$ above the upwind surface, $T_{\mathrm{w}}$ is the temperature of the downwind surface, $Q_{0}$ the specific humidity of air in saturation with a surface at temperature $T_{\mathrm{w}}, L_{\mathrm{v}}$ the latent heat of vapourization $\left(2.5 \times 10^{6} \mathrm{~J} \mathrm{~kg}^{-1}\right), D_{\mathrm{w}}$ the molecular diffusivity of water $\left(2.24 \times 10^{-5} \mathrm{~m}^{2} \mathrm{~s}^{-1}\right.$ at $\left.-1.8^{\circ} \mathrm{C}\right)$ and $\kappa$ is the thermal conductivity of air $\left(2.43 \times 10^{-2} \mathrm{~J} \mathrm{~m}^{-1} \mathrm{~s}^{-1} \mathrm{deg}^{-1}\right.$ at $\left.-1.8^{\circ} \mathrm{C}\right)$. Using additional measurements made downwind of Arctic polynyas, Andreas and Murphy (1986) showed that the above relationships are valid for fetches of up to $500 \mathrm{~m}$.

We use these equations to estimate the average value of the turbulent heat fluxes over an open water lead of fetch $x$, under the same wind and temperature conditions considered in the section on energy exchange over sea ice. The total turbulent loss over the open water lead,

$$
F_{\mathrm{L}}=F_{\mathrm{s}}+F_{\mathrm{e}}
$$

is shown in Figure 3. This illustrates the rapid change in average heat flux with lead width for narrow leads, but, as lead width increases, the air mass approaches equilibrium and the rate of change with fetch decreases. The relative contribution of the two components is given by the Bowen ratio $\left(F_{\mathrm{s}} / F_{\mathrm{e}}\right)$, which varies from approximately 1.7 at $-5^{\circ} \mathrm{C}$, to approximately 3.5 at $-20^{\circ} \mathrm{C}$.

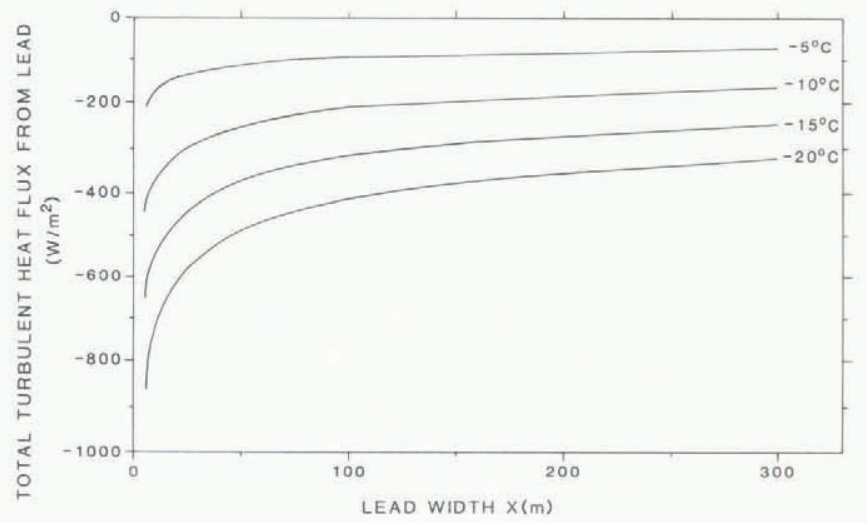

Fig. 3. Variation in the total turbulent heat transfer over leads of varying fetch, for different ambient air temperatures from $-5^{\circ}$ to $-20^{\circ} \mathrm{C}$.

\section{TURBULENT EXCHANGE OVER YOUNG PACK OF VARYING CONCENTRATION}

Having calculated the turbulent heat transfer over thin, snow-free ice and over water surfaces, respectively, it is possible to estimate the total turbulent exchange of heat over a large area within the Antarctic pack, if we assume it to be a mix of both ice floes and leads. To do this fully, the ice-thickness distribution, as well as floe size (lead width) and meteorological variables such as air temperature and wind speed, must be known. However, since there are virtually no data from which these parameters can be determined, other than shipboard observations which are sparse and randomly located, we consider here only young pack ice of varying concentration consisting of floes of uniform ice thickness and a constant size of $100 \mathrm{~m}$, which is typical of the East Antarctic pack away from the ice edge (e.g. Jacka and others, 1987; Allison, 1989).

The turbulent transfer of heat from ocean to atmosphere can be calculated by linearly summing the relative heat-flux contributions from each surface within the sea-ice zone, using the results of the previous sections. Hence, for a single ice thickness category, the average turbulent heat flux $\left(F_{\mathrm{T}}\right)$ is given by

$$
F_{\mathrm{T}}=F_{\mathrm{I}}+F_{\mathrm{L}},
$$

where $F_{\mathrm{I}}$ is the fractional contribution to the turbulent flux from the ice covered area and $F_{\mathrm{L}}$ the fractional contribution from open water (leads).

To simulate varying conditions of ice cover, we assume that the pack is infinitely uniform across wind, and that downwind it is composed of constant width floes $(100 \mathrm{~m})$ interspersed with open-water leads of different width, as shown in Table 1 . The non-linear change of sensible and latent heat flux associated with a step change in the boundary layer over open water has been accounted for in the previous section. We are, however, only considering a "single lead" system, neglecting the cumulative effect of modification of the air mass as it passes over a succession of leads and the similar fetch-dependence of the heat loss over ice.

The calculated contribution from over the ice and the leads, and the area-averaged total turbulent heat loss for pack ice of concentration 100, 80, 65, 50 and 30\%, are shown as a function of different ice thickness and

Table 1. Floe and lead dimensions used to simulate pack ice of different concentrations.

Ice concentration Floe width Lead width
$(\%)$
(m)
(m)

$\begin{array}{rrr}100 & 100 & 0 \\ 80 & 100 & 25 \\ 65 & 100 & 54 \\ 50 & 100 & 100 \\ 30 & 100 & 233\end{array}$


Table 2. Area-averaged total turbulent heat flux $\left(\mathrm{W} \mathrm{m}^{-2}\right)$ over pack ice of different concentration as a function of air temperature and ice thickness $(H) . F_{\mathrm{I}}$ is the fractional contribution to the turbulent flux from the icecovered area, $F_{\mathrm{L}}$ the fractional contribution from open water (leads), and $F_{\mathrm{T}}$ the average turbulent flux over the total region. The lead width used for each concentration category is given in Table 1.

\begin{tabular}{|c|c|c|c|c|c|c|c|c|c|c|}
\hline \multicolumn{2}{|c|}{ Air temperature } & \multicolumn{3}{|c|}{$-5^{\circ} \mathrm{C}$} & \multicolumn{3}{|c|}{$-10^{\circ} \mathrm{C}$} & \multicolumn{3}{|c|}{$-15^{\circ} \mathrm{C}$} \\
\hline Ice conc. & $H(\mathrm{~m})$ & $F_{\mathrm{I}}$ & $F_{\mathrm{L}}$ & $F_{\mathrm{T}}$ & $F_{\mathrm{I}}$ & $F_{\mathrm{L}}$ & $\mathrm{F}_{\mathrm{T}}$ & $F_{\mathrm{I}}$ & $F_{\mathrm{L}}$ & $F_{\mathrm{T}}$ \\
\hline \multirow[t]{4}{*}{$100 \%$} & 0.1 & -53 & 0 & -53 & -103 & 0 & -103 & -168 & 0 & -168 \\
\hline & 0.2 & -38 & 0 & -38 & -63 & 0 & -63 & -92 & 0 & -92 \\
\hline & 0.4 & -28 & 0 & -28 & -38 & 0 & -38 & -56 & 0 & -56 \\
\hline & 0.8 & -24 & 0 & -24 & -22 & 0 & -22 & -29 & 0 & -29 \\
\hline \multirow[t]{4}{*}{$80 \%$} & 0.1 & -42 & -27 & -69 & -82 & -60 & -142 & -134 & -89 & -223 \\
\hline & 0.2 & -30 & -27 & -57 & -51 & -60 & -111 & -73 & -89 & -162 \\
\hline & 0.4 & -22 & -27 & -49 & -30 & -60 & -90 & -45 & -89 & -134 \\
\hline & 0.8 & -20 & -27 & -47 & -17 & -60 & -77 & -23 & -89 & -112 \\
\hline \multirow[t]{4}{*}{$65 \%$} & 0.1 & -34 & -40 & -74 & -67 & -87 & -154 & -109 & -129 & -238 \\
\hline & 0.2 & -25 & -40 & -65 & -41 & -87 & -128 & -60 & -129 & -189 \\
\hline & 0.4 & -18 & -40 & -58 & -25 & -87 & -112 & -37 & -129 & -166 \\
\hline & 0.8 & -16 & -40 & -56 & -14 & -87 & -101 & -19 & -129 & -148 \\
\hline \multirow[t]{4}{*}{$50 \%$} & 0.1 & -26 & -49 & -75 & -51 & -107 & -158 & -84 & -159 & -243 \\
\hline & 0.2 & -19 & -49 & -68 & -32 & -107 & -139 & -46 & -159 & -205 \\
\hline & 0.4 & -14 & -49 & -63 & -19 & -107 & -126 & -28 & -159 & -187 \\
\hline & 0.8 & -12 & -49 & -61 & -11 & -107 & -118 & -15 & -159 & -174 \\
\hline \multirow[t]{4}{*}{$30 \%$} & 0.1 & -16 & -56 & -72 & -31 & -122 & -153 & -50 & -182 & -232 \\
\hline & 0.2 & -11 & -56 & -67 & -19 & -122 & -141 & -27 & -182 & -209 \\
\hline & 0.4 & -8 & -56 & -64 & -11 & -122 & -133 & -17 & -182 & -199 \\
\hline & 0.8 & -7 & -56 & -63 & -7 & -122 & -129 & -9 & -182 & -191 \\
\hline
\end{tabular}

air temperature in Table 2. Consider first the results for an ice concentration of $80 \%$, typical of the average concentration off East Antarctica in September. At an air temperature of $-10^{\circ} \mathrm{C}$, the turbulent heat flux over ice $0.4 \mathrm{~m}$ thick is $-38 \mathrm{~W} \mathrm{~m}^{-2}$, whilst the turbulent flux over a $25 \mathrm{~m}$ lead is $-300 \mathrm{~W} \mathrm{~m}^{-2}$. Hence, from Equation 12 , the total average turbulent flux for $80 \%$ concentration ice is $-90 \mathrm{~W} \mathrm{~m}^{-2}$. A decrease in ice thickness to $0.2 \mathrm{~m}$ increases the turbulent flux over the ice surface to $-63 \mathrm{~W} \mathrm{~m}^{-2}$ and the average flux over the region of $80 \%$ concentration to $-111 \mathrm{~W} \mathrm{~m}^{-2}$. A further decrease in $H$ to $0.1 \mathrm{~m}$ causes an even larger increase in $F_{\mathrm{T}}$ in response to the larger changes in ocean-atmosphere heat exchange over the thinnest categories of ice. For this ice thickness, the average turbulent heat flux over the region is $-142 \mathrm{~W} \mathrm{~m}^{-2}$. These, and the results for other ice thicknesses and air temperatures, are shown in Figure 4. Note that the turbulent heat flux over ice of only $0.1 \mathrm{~m}$ thickness varies markedly, depending on air temperature, with a range from $-53 \mathrm{~W} \mathrm{~m}^{-2}$ at $-5^{\circ} \mathrm{C}$ to $-224 \mathrm{~W} \mathrm{~m}^{-2}$ at $-20^{\circ} \mathrm{C}$. The flux over this very thin ice, regardless of the air temperature, is the major contributor to the areaaveraged turbulent heat flux for an ice concentration of $80 \%$. That is, the turbulent heat flux over $100 \mathrm{~m}$ of $0.1 \mathrm{~m}$ thick ice exceeds that over a $25 \mathrm{~m}$ lead.

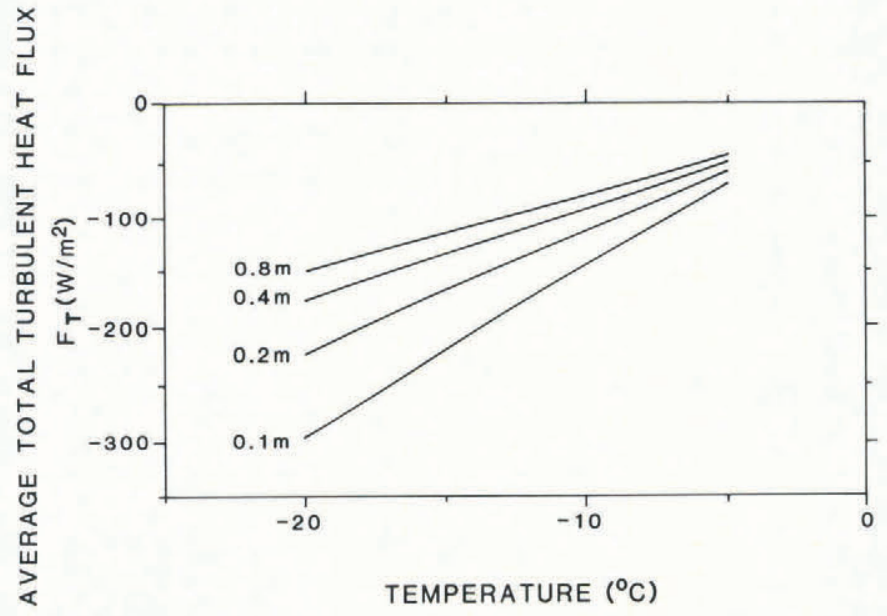

Fig. 4. Variation in the average turbulent heat flux over an ice-water surface of $80 \%$ concentration, where floe size equals $100 \mathrm{~m}$ and lead size equals $25 \mathrm{~m}$. The heat flux is shown for a range of ice thicknesses from $0.1 \mathrm{~m}$ to $0.8 \mathrm{~m}$.

As ice thickness increases, $F_{\mathrm{L}}$ rapidly becomes dominant, although the area-averaged total turbulent heat flux begins to decrease. An increase in $H$ from $0.1 \mathrm{~m}$ to $0.2 \mathrm{~m}$ shows how rapidly the contribution of $F_{\mathrm{I}}$ falls 
as the ice thickens. For $H=0.2 \mathrm{~m}$, the contribution of $F_{\mathrm{L}}$ already exceeds that of $F_{\mathrm{I}}$ for air temperatures below $-5^{\circ} \mathrm{C}$, and for $0.4 \mathrm{~m}$ thick ice the contribution from the leads at colder temperatures is about double that from the ice-covered area. However, the turbulent heat transfer over $0.4 \mathrm{~m}$ thick ice is by no means negligible, and makes an important contribution to the total turbulent heat exchange $\left(F_{\mathrm{T}}\right)$ in the sea-ice zone. It is clear that at $80 \%$ concentration, and for conditions where there are extensive areas of thin ice (as observed in the Antarctic), the turbulent fluxes over the ice may contribute to the total heat budget of the region on a scale similar to that of the turbulent fluxes over open water.

The total turbulent heat losses for other ice concentrations, using the assumptions in Table 1 , are given in Table 2. As expected, the decrease in concentration generally results in an increase in $F_{\mathrm{T}}$ for each thickness of ice because of increased heat loss from leads. (The apparently greater flux for $50 \%$ compared to $30 \%$ ice of $0.1 \mathrm{~m}$ thickness occurs because the turbulent fluxes from wide leads calculated by Equations (9) and (10) are not completely identical to the open-water loss calculated using the bulk aerodynamic assumptions of the section on energy exchange.) In our model, the turbulent heat loss (per unit area) from floes has no fetch dependence and is not altered by changes in ice concentration. However, as concentration decreases, the turbulent fluxes over the ice contribute less to the total heat flux of the region. Over leads, the turbulent heat fluxes at any point, $x$, remain constant despite changes in ice concentration or distribution, but the average flux over leads varies considerably and non-linearly as the leads increase. Whilst decreasing concentration (increasing lead width) causes a decrease in the average turbulent heat flux per unit area from the open water, there is, as a result of the larger area of open water, an increase in the total flux.

Figure 5 shows the variation in $F_{\mathrm{T}}$ with changing ice concentration for an air temperature of $-10^{\circ} \mathrm{C}$. The non-linear nature of the relationship between concentration and the total turbulent transfer of heat is clearly

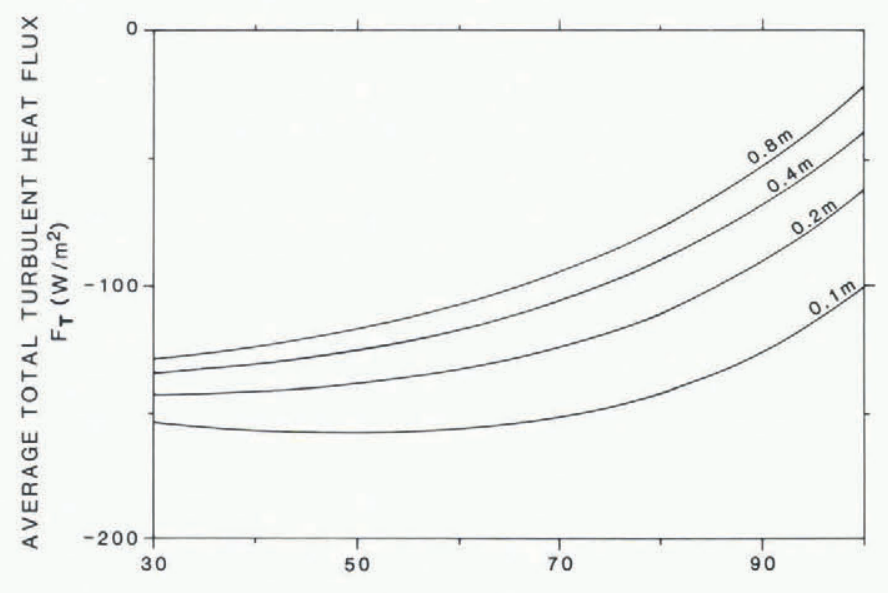

ICE CONCENTRATION (\%)

Fig. 5. Variation in the average turbulent heat flux over a mixed ice-water surface as a function of ice thickness and ice concentration, at an air temperature of $-10^{\circ} \mathrm{C}$. The heat flux is shown for a range of ice thicknesses from $0.1 \mathrm{~m}$ to $0.8 \mathrm{~m}$. illustrated. As concentration decreases from $100 \%$ ice cover to $80 \%$, there is a rapid change (of approximately $50 \mathrm{~W} \mathrm{~m}^{-2}$ ) in the loss of turbulent heat to the atmosphere. The rate of increase of $F_{\mathrm{T}}$ slows as concentration is further decreased and the turbulent heat fluxes from the open water have a lesser effect on the total areaaveraged flux. This is because a decrease in concentration is effectively only increasing lead width and the air over the "additional" water has already been modified by the water surface immediately upwind. This serves to highlight the importance of air modification over leads and the necessity of taking account of these processes in heat flux calculations.

\section{DISCUSSION AND CONCLUSIONS}

In considering the results presented above, it is important to keep in mind the limitations of the simple model used. First, we have considered only thin ice $(<0.8 \mathrm{~m})$ of uniform thickness. Whereas the observations of Brandt and others (1990) in the Indian Ocean sector show that, at a distance from the ice edge greater than $500 \mathrm{~km}$, about $30 \%$ of the pack is thicker than $0.7 \mathrm{~m}$, the greater percentage of thin ice will be much more important in determining the total turbulent transfer of heat. We also consider only snow-free ice but even 2 or $3 \mathrm{~cm}$ of snow on thin ice can have a large effect on surface temperature and, hence, on the turbulent fluxes. However, Brandt and others (1990) observed that ice less than $0.15 \mathrm{~m}$ thick was almost always snow-free, and that ice between 0.15 and $0.3 \mathrm{~m}$ was either snow-free or had a snow cover of less than $0.03 \mathrm{~m}$. Therefore, the assumption of snow-free ice is probably not unreasonable as a first step for determining the impact of extensive areas of thin ice on the turbulent heat exchange.

More importantly, in estimating the effect of concentration on total heat loss, we have considered only a constant floe size of $100 \mathrm{~m}$. If a different flow size, and appropriate lead widths, were taken then the magnitude of the estimated fluxes would change somewhat. With smaller floes and narrower leads, the loss from the leads is greater and the area-averaged heat flux increases more rapidly with a concentration decrease from $100 \%$. With large floes and wider leads, the opposite occurs but, in both cases, the sensitivity of the total heat loss to concentration change remains greatest at high concentrations and approaches zero below $50 \%$. In part, the sensitivity of the results to the assumed floe size arises because of another of our assumptions. We consider only a "single-lead" system and do not allow for the cumulative effect of passage over successive leads and floes, nor for a fetch dependence on the turbulent heat loss over the floes. Qualitatively, the cumulative modification of the air mass would tend to decrease the total flux, particularly at higher concentrations and for narrower leads, counteracting the effect of a decrease in the assumed flow size.

Apart from temperature, which is treated as a sensitivity parameter, we consider only one set of climatic forcing. Thus, while it is not totally appropriate to make comparisons, our results are nevertheless in general agreement with other studies for similar ice conditions. For example, Weller (1980) estimated a mid-winter turbulent loss of $-117 \mathrm{~W} \mathrm{~m}^{-2}$ over his inner Antarctic zone 
( $80 \% 0.8 \mathrm{~m}$ thick ice plus $10 \% \quad 0.2 \mathrm{~m}$ thick ice). Our results for $90 \% 0.8 \mathrm{~m}$ thick ice give a total loss of $-105 \mathrm{~W} \mathrm{~m}^{-2}$ at $-20^{\circ} \mathrm{C}$ and $-54 \mathrm{Wm}^{-2}$ at $-10^{\circ} \mathrm{C}$. Over his outer zone $(40 \% 0.8 \mathrm{~m}$ thick ice, plus $20 \% 0.2 \mathrm{~m}$ thick ice), Weller estimated a flux of $-189 \mathrm{~W} \mathrm{~m}^{-2}$, whereas for $60 \% 0.8 \mathrm{~m}$ thick ice our turbulent loss is $-108 \mathrm{~W} \mathrm{~m}^{-2}$ at $-10^{\circ} \mathrm{C}$ and $-205 \mathrm{~W} \mathrm{~m}^{-2}$ at $-20^{\circ} \mathrm{C}$.

Despite the limitations of the model, the results of this sensitivity study do show a number of additional features that we might expect intuitively. Of major importance is the indication that, if the Antarctic pack contains as much thin ice as recent observations suggest, the heat loss through this thin ice is significant compared even to the loss over open water. At $80 \%$ ice concentration the turbulent heat loss through thin ice can be greater than that from open water. As concentration decreases, however, the fractional loss through the ice and, hence, the thickness of the ice, becomes less significant. This is in sharp contrast to the situation in the central Arctic, where Maykut (1982) calculated area-weighted total turbulent heat loss taking account of the ice-thickness distribution. For March he estimated that less than $8 \%$ of the pack was open water or thin ice and the total turbulent transfer was dominated by transfer over the large area of thick ice.

Secondly, changes in ice concentration or in ice thickness both significantly modify the turbulent energy exchange over high concentration pack ice but, for ice concentration less than about $50 \%$, there is effectively no change in the total turbulent heat loss for a change in concentration. At the same time, the effect of ice thickness becomes less important at low concentration since the heat lost through the floes represents a decreasingly significant percentage of the total.

\section{REFERENCES}

Allison, I. 1989. The East Antarctic sea ice zone: ice characteristics and drift. GeoJournal, 18(1), 103-115.

Andreas, E.L. 1980. Estimation of heat and mass fluxes over Arctic leads. Mon. Weather Rev., 108, 20572063.

Andreas, E.L. 1982. Sensible and latent heat fluxes and humidity profiles following a step change in surface moisture. CRREL Rep., 82-12.

Andreas, E.L. and B. Murphy. 1986. Bulk transfer coefficients for heat and momentum over leads and polynyas. J. Phys. Oceanogr., 16, 1875-1883.

Andreas, E.L., C.A. Paulson, R.M. Williams, R.W. Lindsay, and J.A. Businger. 1979. The turbulent heat flux from Arctic leads. Boundary-Layer Meteorol., 17, 57-91.

Brandt, R., I. Allison, and S. Warren. 1990. Albedo of young and first-year Antarctic sea ice. (Abstract.) Ann. Glaciol., 14, 331.

Budyko, M.I., ed. 1963. Atlas teplovogo balansa zemnogo shara [Atlas of the heat budget of the Earth's surface]. Moscow, Glavnaya Geofizicheskaya Observatoriya.

Fletcher, J.O. 1969. Ice extent on the Southern Ocean and its relation to world climate. Santa Monica, CA, Rand Corporation. (Memo. RM-5793-NSF.)
Gow, A.J., S.F. Ackley, W.F. Weeks, and J.N. Govoni. 1982. Physical and structural characteristics of Antarctic sea ice. Ann. Glaciol., 3, 113-117.

Jacka, T.H., I. Allison, R. Thwaites, and J.C. Wilson. 1987. Characteristics of the seasonal sea ice of East Antarctica and comparisons with satellite observations. Ann. Glaciol., 9, 85-91.

Jenne, R.L., H.L. Crutcher, H. van Loon, and J.J. Taljaard. 1974. Selected climatology of the Southern Hemisphere: computer methods and data availability. National Center for Atmospheric Research Tech. Note STR-92.

Maykut, G.A. 1978. Energy exchange over young sea ice in the central Arctic. J. Geophys. Res., 83(C7), 3646-3658.

Maykut, G.A. 1982. Large-scale heat exchange and ice production in the central Arctic. J. Geophys. Res., 87(C10), 7971-7984.

Maykut, G.A. and N. Untersteiner. 1971. Some results from a time-dependent thermodynamic model of sea ice. J. Geophys. Res., 76(6), 1550-1575.

Press, W.H., B.P. Flannery, S.A. Teukolsky, and W.T. Vetterling. 1986. Numerical recipes in $C$; the art of scientific computing. Cambridge, Cambridge University Press.

Southern, B.N. 1989. Sea ice concentration and drift in Prydz Bay. Antarctic Science and Advisory Committee. Conference and Workshop on Antarctic Weather and Climate held at Flinders Institute for Atmospheric and Marine Sciences, Flinders Institute of South Australia, 5-7 July 1989. Extended abstracts.

Wadhams, P., M.A. Lange, and S.F. Ackley. 1987. The ice thickness distribution across the Atlantic sector of the Antarctic Ocean during winter. J. Geophys. Res., 92(C13), 14,535-14,552.

Warren, S.G., C.J. Hahn, J. London, R.M. Chervin, and R.L. Jenne. 1988. Global distribution of total cloud cover and cloud type amounts over the ocean. Washington, DC, US Department of Energy. (DOE/ER-0406; NCAR/TN-317+STR; NCAR Tech. Notes)

Weller, G. 1967. Radiation fluxes over an Antarctic ice surface, Mawson, 1961-62. ANARE Sci. Rep., Ser. A (IV), Glaciol. Publ. 96.

Weller, G. 1980. Spatial and temporal variations in the south polar surface energy balance. Mon. Weather Rev., 108(12), 2007-2014.

Zillman, J.W. Unpublished. A study of some aspects of the radiation and heat budgets of the Southern Hemisphere oceans. (M.Sc. thesis, University of Melbourne, 1970.)

Zwally, H.J., J.C. Comiso, C.L. Parkinson, W.J. Campbell, F.D. Carsey, and P. Gloersen. 1983. Antarctic sea ice, 1973-1976: satellite passive-microwave observations. Washington, DC, National Aeronautics and Space Administration. (NASA Special Publication 459.)

The accuracy of references in the text and in this list is the responsibility of the authors, to whom queries should be addressed. 